\title{
THE ORGANIZATION'S SAFETY CULTURE, ITS INDICATORS AND ITS MEASUREMENT CAPABILITIES Martin Halaj ${ }^{1}$, Milan Kutaj ${ }^{2}$, Martin Boroš ${ }^{3}$
}

\begin{abstract}
Safety is a fundamental condition for the existence of an organization creating conditions for the fulfilment of its basic functions. It is important to identify the safety factors that affect an organization's level. In this article, we identify and describe one of these factors, which is a safety culture. In order to assess a safety culture, its indicators have to be identified. Safety culture indicators reflect its level in various areas. Some of the indicators of safety culture are universal and usable in a large number of organizations, while some of them are more specific and usable only for certain organizations. After identifying the critical thresholds of all safety culture indicators identified, they can be used to assess the final level of safety culture. It is crucial to propose the right combination of methods and practices, while also using safety culture indicators to determine this final level of safety culture. In this article we present a combination of two data obtaining tools: a questionnaire survey conducted among the employees of the organization and managed interviews with the management of the organization. In order to properly evaluate the safety culture, it is necessary to compare the obtained data. The main contribution of the article is the proposal of a possible scheme for assessing the safety culture of organizations using the safety culture indicators.
\end{abstract}

UDC Classification: 304; DOI: http://dx.doi.org/10.12955/cbup.v6.1219

Keywords: safety, safety culture, safety culture indicators

\section{Introduction}

The goal of each organization is to ensure its existence and constant progress and development. Security has a major impact on this goal. Security itself is a complex, internally structured, multifactor and hierarchical phenomenon. Its content, structure and functions go beyond the boundaries of leading departments and fields of science (Hofreiter, 2006).

The security of an organization is characterized as a constant efficient use of an organization's available resources, which ensure its stable functioning at the present and its continuous development into the future. An organization can be considered safe if it is not a source of threat, and it does not endanger itself or its surroundings. Its steady state allows its constant development and the active fulfilment of its set goals. It is able to eliminate and minimize internal and external threats of different nature while being able to respond to them by changing their state or environment.

The security of the organization affects internal and external factors such as: the security environment, threat, vulnerability, resilience, or safety culture. Safety culture has, besides the level of organization security, an impact on the development of other factors. These factors need to be explored and expanded.

\section{Safety culture}

The term safety culture combines the notions of safety and culture. This term was first used in 1986 by the International Atomic Energy Agency (IAEA) after the Chernobyl nuclear reactor accident. The IAEA found that the main reason for the reactor overheating was the lack of the organization's safety culture (Slováčková, 2015).

In addition to nuclear facilities, safety culture has also, over time, been integrated into other industries. Safety culture has begun to be used as a tool to reduce or eliminate the impact of undesirable events and factors relating to individuals, social groups or the state (Hofreiter, 2015).

Cieślarczyk (2011) sees safety culture as a way of thinking about security, perceiving security and detecting security values.

Lee defines an organization's safety culture as the result of individual and group values, attitudes and behaviors that reflect the organization's commitment to health and safety at work (Guldenmund, 2010).

Berends (1993) says that security culture is influenced by the subconscious behavior of security staff in organizations.

\footnotetext{
${ }^{1}$ Faculty of Security Engineering, University of Žilina, Slovakia, martin.halaj@ fbi.uniza.sk

${ }^{2}$ Faculty of Security Engineering, University of Žilina, Slovakia, milan.kutaj@fbi.uniza.sk

${ }^{3}$ Faculty of Security Engineering, University of Žilina, Slovakia, martin.boros@fbi.uniza.sk
} 
Ostorm understands safety culture as a set of opinions and attitudes of the organization that manifest themselves in its activities, practices, policies and have a major impact on the organization's overall security (Guldenmund, 2010).

We can define a culture of security as a set of values, traditions, characteristics and attitudes of the organization and its individuals. A safety culture attaches the highest priority to safety, and therefore, it must be given adequate attention.

The level of a security culture is also directly conditioned by the correct response to emerging dangerous (crisis) situations. A safety culture can be expressed as a synergy of human factor with its security capabilities and skills (mental, spiritual pillar), technical and technological means (material pillar) and organizational measures to ensure security (organizational pillar).

$$
S C=S P_{\triangle M} P_{\triangle O P}
$$

Where:

SC - Safety culture

SP - Spiritual pillar

MP - Material pillar

OP - Organizational pillar

\section{The organization's safety culture}

Safety culture affects an organization's security management through the existence of rules, laws, regulations and standards. It is important for every organization to adopt a safety culture.

A safety culture must be supported by the following factors (Halaj \& Hofreiter, 2017):

- the commitment of senior management to security management,

- successful treatment of risks and their impacts,

- established of valid standards and rules on risks,

- constantly progressing and learning from mistakes.

An organization's safety culture means accepting safety by an organization in order to achieve protection and security of its activities, and the health and safety of its employees.

The first step in identifying a safety culture in an organization is the existence of a security policy. A security policy is an important and basic set of rules, confirming the effort to address security issues in all its sectors. A security policy can be compiled for the whole organization or individually for each sector separately. In addition to the managers, the staff's professional competence, which is needed to solve the unwanted events, has an important role to play in the organization's security policy. The organization's safety culture is based on the reception and identification of employees with the organization's security policy and their safe conduct within the organization (Halaj \& Hofreiter, 2017).

An organization's safety culture is affected by the adoption of security measures by senior management, allocating sufficient resources to safety, quality of safety documentation and safety procedures, strict observance of safety in all sectors of the organization, safety training and educations, the readiness of the organization to deal with adverse crisis events and obstructions by assigning permanently accessible forces and means and by regular checks, and to continuously improve an organization's safety (Hofreiter, 2015).

Based on research and the experience of misconduct of organizations in the security management process, contradictions are increasingly emerging in recent years as to what are the basic characteristics of a safety culture. It is necessary to state the characteristics of a safety culture based on its structure, artefacts, values and assumptions.

The assumption that the organization's top management actively proclaims security is considered the artefact of the organization's safety culture. The findings and the corrective actions taken to remove the shortcomings identified should be supported by quality documentation. Organizations are required to comply with their obligations under laws and standards and to ensure the professional competence of all their employees for whom the nature of their work requires them to. It is important to allocate sufficient resources to this process as well as to a regular security assessment.

The most important value of an organization's safety culture is to emphasize the importance of security in the organization. This is what the leadership, as well as the employees themselves, must acquire and 
identify with. Security needs to be constantly increasing, it is necessary to constantly communicate about it and to broaden the knowledge about the possibilities of its achievement.

\section{Safety culture indicators}

For the need of assessing the level of safety culture, it is important to identify areas that reflect security in each sector and which can be actively monitored.

Indicator in this regard is a synonym for the term "pointer". The pointer is a value whose character may vary from one pointer to another. The pointer expresses status or its changes (Hanušin, et al., 2000). The occurrence of the indicator indicate with different degrees of probability the occurrence of another phenomenon or parameters (Szarfenberg, 2018).

The indicator is a visible phenomenon or a thing that indicates changes and makes it possible to predict other phenomena. It is difficult to find a uniform definition for indicators because each area of research has adopted and used its own definitions. The goal of indicators is to describe the system, its properties and various parameters as simply and accurately as possible.

The main functions of indicators are (Hofreiter \& Byrtusová, 2016):

- descriptive function

- interconnective function

- analytical function

- predictive function

Organizational safety culture indicators indicate or reflect a level of safety, serve to measure its level effectively, and determine the success of the objectives. It is necessary for safety indicators to be reasonably visible, identifiable and measurable (Belan, 2015). Based on the character of their indicators and their ability to express them (qualitatively, quantitatively), they can be used to measure and assess the level of a safety culture.

We can classify two groups of organizational safety culture indicators:

- reactive indicators - indicating the number of specific safety events for a precisely time-bound period (Belan, 2015) and can be defined ex post using the deductive method (Hofreiter \& Byrtusová, 2016),

- predictive indicators - are focused on monitoring critical location processes and assessing potential accidents (Belan, 2015) and are built ex ante and enable effective security systems and security measures to be developed (Hofreiter \& Byrtusová, 2016).

Safety culture indicators may be:

- objective - statistical values of the indicators,

- subjective - individual perceptions of safety.

Thanks to safety culture indicators, it is possible to identify safety culture's status in the organization and its sectors. Organizational safety culture indicators may be generally valid for most organizations, but each organization may have specific indicators that reflect its character, size or type. For the purposes of this paper, we identify the indicators that are part of each organization and can be supplemented as necessary. These indicators are:

- the importance of security for an organization's management,

- the importance of security for the staff of an organization,

- creating and implementing security policy,

- the amount of money spent on security,

- implementation of policy and continuous training in the field of safety,

- required professional competence of employees,

- compliance with laws and safety standards,

- the organization's preparedness to deal with crisis situations,

- the frequency of attempted disruption on the organization's premises,

- the number of accidents and occupational diseases,

- safety awareness of the organization's employees and their safety behaviour,

- identification of established procedures and tasks in the security sector,

- cleanliness and order at the workplace. 
In order to explore safety culture indicators, it is necessary to set their thresholds, which represent a limit value overtaken by a safety breach or an insufficient level of safety culture in each security sectors of the organization. If indicator values approach their thresholds, this may mean degradation of the system or its transition to a new state. Such approximation or achievement of the threshold may pose a threat to the security of the organization and its surroundings (Hofreiter \& Byrtusová, 2016). The thresholds for safety culture indicators vary from one organization to another. Significant factors are, in particular, the focus and size of organizations in which indicators are identified.

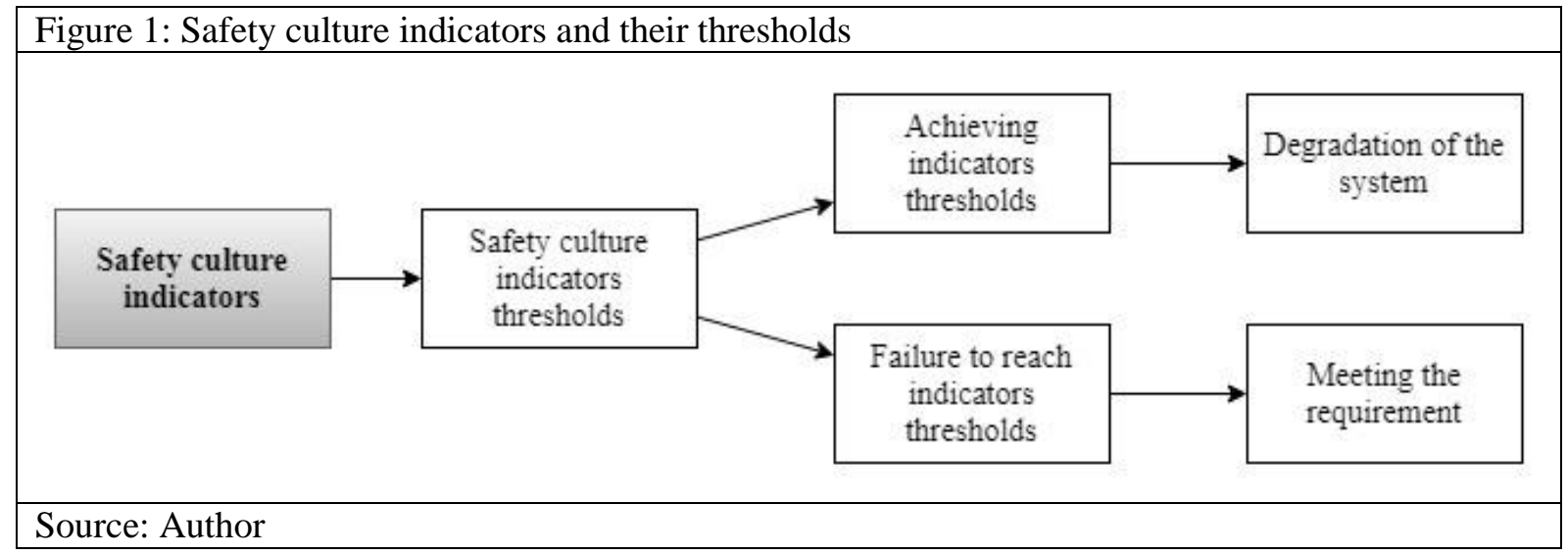

\section{Methods of measuring a safety culture using safety culture indicators}

The first step in measuring the level of safety culture is to identify its indicators. After successfully identifying the indicators, we are able to identify the areas that need to be addressed in recognizing the level of safety culture.

So far, there are no accurately described and established possible methods or tools for measuring a safety culture in organizations. Based on our active dedication to this issue, we propose a way of measuring this level, which consists of the following parts:

- conducting a questionnaire survey among the employees of the organization,

- conducting structured interviews with organization management.

\section{Questionnaire survey among employees of the organization}

The questionnaire is an economic research, developmental and evaluation tool for mass and relatively quick detection of information (Gavora, 2001), (Švec, 1998). Through the questionnaire we can get information about what people do, what they own, what they think, know, feel, live or want, what values they prefer, what their opinion is and how they can uncover their life experiences (TaylorPowell, 2018). We can examine:

- knowledge,

- beliefs, opinions, attitudes,

- behaviour,

- features, characters, features.

The questionnaire method is based on the subjective testimony of the investigated person about its properties, emotions, attitudes, opinions, and interests. The task of the investigated person is to mark out a statement that, in their opinion, describes the character examined the best. It is a method of indirect assessment because the investigated person does not look directly at the personality trait, but rather describes his behaviour in certain situations that the observed property can be manifest (Svoboda, 2005).

Getting data from questionnaires from a relatively large number of respondents is not costly and allows for more detailed statistical analysis of the results. However, preparation of questionnaire survey may be difficult in time. The confidentiality of information is important in order to be able to expect honest answers even for unpleasant questions. A well-structured questionnaire will provide answers to more general questions as well as more specific questions.

Such questionnaire survey should involve as many staff as possible in order to ensure that its results reflect a fair presentation of the real situation. Questionnaire questions must be linked to selected 
indicators of the safety culture and the area surveyed. From the results of the questionnaire, we need to get information that we can work with.

\section{Structured interviews with organization management}

The method of managed interviews is a useful method of collecting data especially in social research. It is a system of placing pre-prepared questions and recording the subsequent answers of the selected respondents. The obtained data must be statistically processed and evaluated. The advantage of this method is that the performance of the survey is higher compared to the questionnaire method, but this method is costlier and time consuming. The person who conducts the interview needs to be duly oriented in the matter, which may affect some of the respondents. A partial disadvantage of this method is the lack of anonymity for the respondents.

Because of its time consuming nature and the inability to maintain anonymity, this method should be used to explore the safety culture in the management of the organization. Pre-prepared questions should include and expand the selected safety culture indicators and the selected security areas. Respondents' answers should be comprehensive. Answers should reflect the organization's security and its implementation. The goal of structured interviews with the organization's management is to gain data about security and the application of a safety culture.

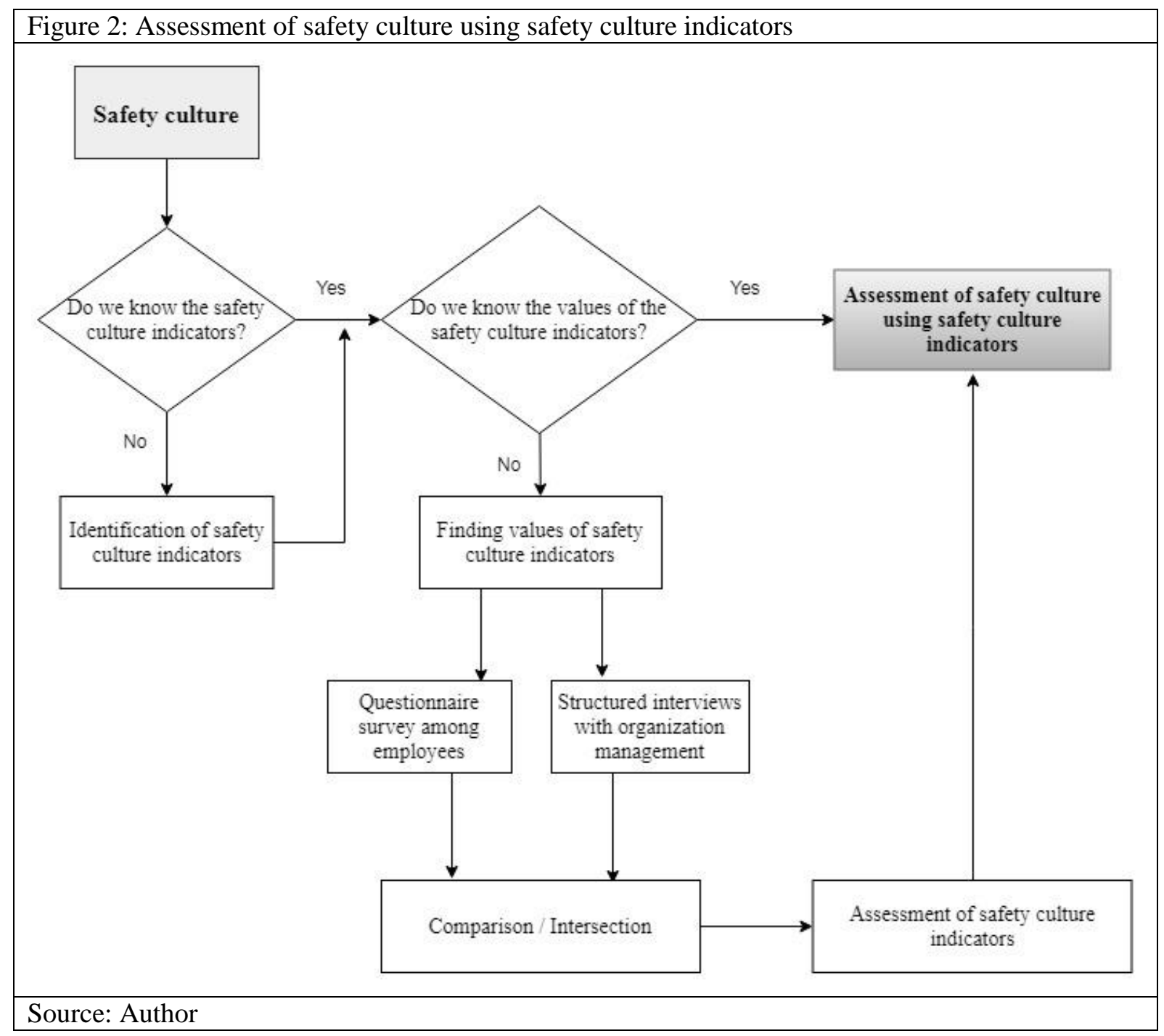

\section{Comparison of collected data}

The results of the implemented methods and the answers of each respondents should be properly compared. This comparison will serve to determine the match and possible differences in responses. Disagreements between the result of the questionnaire and the structured interviews should be analysed using expert estimates and drawn conclusions. 
The results from the comparison of the performed methods' will be the assignment of an evaluation to the selected safety culture indicators. During the assessment of the assigned values of safety culture indicators, it is necessary to address their (predetermined) thresholds. The safety culture indicators' threshold values are one of the tools to analyse security system and are part of the quantification and assessment of the organization's safety culture resulting state. Based on the above, we can determine the resulting level of the organization safety culture by assigning values to the selected safety culture indicators. However, we must take their critical thresholds and mutual relations into account as well.

The process of evaluating a safety culture using its identified safety culture indicators is shown in Figure 2.

\section{Conclusion}

Security assures organizations their existence, persistence and constant development. Organizational security needs to be constantly observed, evaluated and enhanced. For these reasons, we need to know the factors that affect security. Safety culture reflects the standards, values and attitudes of the organization and its staff to security and safety.

We need to know safety culture indicators to assess it. Safety culture indicators should be used as a basis for assessing the level of the safety culture. We propose to use two methods of data collection. A questionnaire survey among employees of the organization and structured interviews with the organization's management. The questions of these surveys must be linked to safety culture indicators. In a further examination of this problem, the proposed methods need to be applied to a suitable number of selected organizations. Only an empirical approach to addressing these issues can identify any possible shortcomings. Removing these shortcomings will make the assessment of the safety culture simpler and more efficient.

\section{Acknowledgment}

This article was supported by the Internal Grant Scheme of Faculty of Security Engineering, University of Zilina from the grant No. 201702.

\section{References}

Belan, L. (2015). Security management. Security and risk management. Žilina: EDIS.

Berends, J. (1996). On the measurement of safety culture. Eidhoven: University of technology, Eidhoven.

Cieślarczyk, M. (2011). Culture of security and defense. Siedlce: Publisher of the University of Natural Sciences and Humanities.

Gavora, P. (2001). Introduction to pedagogical research. Bratislava: Comenius University.

Guldenmund, F. W. (2010). Understanding and exploring safety culture. Oisterwijk: Proefschriftmaken.nl.

Halaj, M., \& Hofreiter, L. (7 2017). Engineering of organization's security. International Journal of Engineering Research and Technology, 622-666.

Hanušin, J., Huba, M., Ira, V., Klinec, I., Podoba, J., \& Szollos, J. (2000). Interpretative dictionary of sustainability terms. Bratislava: STUŽ/SR.

Hofreiter, L. (2006). Securitology. Liptovský Mikuláš: AOS.

Hofreiter, L. (2015). Security culture and security management. Crisis Management(2), 63-68.

Hofreiter, L., \& Byrtusová, A. (2016). Security indicators. Zlín: VeRBum.

Slováčková, I. (April 2015). Why and how to measure the safety culture of organization. Safety of work in practice, 2-4.

Svoboda, M. (2005). Psychological diagnostics of adults. Prague: Portál.

Szarfenberg, R. (2018, 3 14). Marginalization and social exclusion. Retrieved from Indicators, criteria and meters: http://rszarf.ips.uw.edu.pl/wykluczenie/miws04.pdf

Švec, Š. (1998). Methodology of the science of education. Bratislava: IRIS.

Taylor-Powell, E. (2018, 3 14). Questionnaire Design: Asking questions with a purpose. Retrieved from Better Evaliuation: https://learningstore.uwex.edu/Assets/pdfs/G3658-02.pdf 